\title{
BMJ Open Gym exercising patterns, lifestyle and high-risk sexual behaviour in men who have sex with men and in heterosexual men
}

\author{
Z Mor, ${ }^{1}$ K Parfionov, ${ }^{2,3}$ N Davidovitch, ${ }^{4}$ I Grotto ${ }^{3,5}$
}

To cite: Mor Z, Parfionov K, Davidovitch N, et al. Gym exercising patterns, lifestyle and high-risk sexual behaviour in men who have sex with men and in heterosexual men. BMJ Open 2014;4:e005205. doi:10.1136/bmjopen-2014005205

- Prepublication history and additional material is available. To view please visit the journal (http://dx.doi.org/ 10.1136/bmjopen-2014005205).

Received 7 March 2014 Revised 28 August 2014 Accepted 11 September 2014

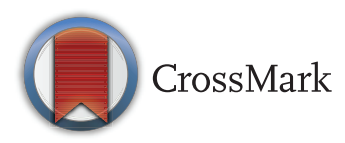

${ }^{1}$ Ramla Health Department, Ministry of Health, Ramla, Israel

2Eating Disorders Unit, Sheba Medical Center, Tel

Hashomer, Israel

${ }^{3}$ Department of

Epidemiology, Faculty of Medicine, Ben Gurion

University in the Negev, Beer Sheva, Israel

${ }^{4}$ Department of Health Policy, Faculty of Medicine, Ben Gurion University in the Negev, Beer Sheva, Israel ${ }^{5}$ Public Health Services, Ministry of Health, Jerusalem, Israel

\section{Correspondence to}

Dr Zohar Mor;

zohar.mor@rml.health.gov.il

\section{ABSTRACT}

Objective: Lifestyle may be associated with risk behaviours. This study compares gym exercise and sexual risk behaviour between men who have sex with men (MSM) and heterosexual men. The research was based on the assumption that men who become muscular and physically attractive increase their number of sex partners and consequently their risk of HIV or other sexually transmitted infections (STIs).

Setting: Five gyms in central Tel Aviv, Israel.

Participants: In 2012, a sample of 182 (48\%) MSM and $197(52 \%)$ heterosexual men who train in gyms completed anonymous questionnaires regarding their training, health and sexual behaviours.

Outcomes: Participants in this cross-sectional study who exercised more than the median number of anaerobic training hours were defined as performing intensive anaerobic training (IAT), and those who had performed more than one act of unprotected anal/ vaginal intercourse in the preceding 6 months with a partner whose HIV status was unknown were defined as high risk.

Results: MSM showed a stronger desire to become muscular than heterosexual men, were more likely to perform IAT, and used protein powders or anabolic steroids. They reported that improving their body shape and increasing their self-confidence were their main reasons for training, whereas heterosexual men indicated weight loss and health improvement as the main reasons for training. MSM engaged in riskier sexual behaviour than heterosexual men. Of all the high-risk men, $61.9 \%(\mathrm{~N}=70)$ performed IAT, while $38.1 \%(\mathrm{~N}=43)$ performed moderate anaerobic training $(p<0.01)$. The association between IAT and sexual risk was stronger in MSM than in heterosexual men ( $p<0.01$ vs $p=0.05$, respectively). The interaction between MSM and IAT in high-risk participants was multiplicative.

Conclusions: MSM practised more IAT than heterosexual men, and their interaction between IAT and sexual risk was multiplicative. The MSM community could benefit from a holistic approach to sexual health and its association with body image and IAT. The gym MSM culture demonstrates how internal dynamics and social norms are possible factors driving MSM to high-risk behaviour for HIV/STI.

\section{Strengths and limitations of this study}

- This is the first study performed in Israeli gyms on non-MSM (men who have sex with men)-oriented premises. As MSM in developed countries share similar cultural norms and behaviours, the results of this study and the multiplicative interaction between intensive anaerobic training (reflected by body image) and sexual risk may be used by health professionals who wish to initiate interventions aiming to reduce sexual risk among MSM.

- The study provides a detailed description of the perceptions of the MSM internal world, including their personal and social driving forces for shaping their masculinity and additional trajectories relating personal traits and sexual risk.

- This study was based on non-probability sampling, which may limit generalisability; it focuses only on MSM who train in gyms, and the data were self-reported and subject to reporting and recall bias.

Study registration: The study was approved by the Wolfson Hospital Review Board, Holon, Israel (WOMC0058-09).

\section{INTRODUCTION}

Body image and masculinity are important aspects of identity in many men who have sex with men (MSM). ${ }^{1}$ Body image is a multidimensional construct of the self, consisting of how one feels and behaves regarding one's own physical attributes ${ }^{2}$ and correlates with well-being. MSM who develop a muscular body shape are usually considered more attractive and gain more self-confidence, while those who fail to fulfil these aesthetic standards are less desirable and more likely tom be avoided by other men. ${ }^{4}$ The shaping of a muscular body has become a symbol of health, ${ }^{5}$ and MSM train in the gym in order 
to keep fit as a way of expressing that they are fit. Another theory is that the efforts of MSM to develop a muscular body are to counteract memories of having a less athletic, or even weak or feminine, appearance during their childhood and adolescence. ${ }^{6}$

In order to become physically attractive, some men train to increase muscle mass, shifting the focus of their training from aerobic to anaerobic training, and perform excessive muscle-strengthening exercises rather than improving their cardiac performance. ${ }^{7}$ In addition, as gym training is an important component of the internal MSM culture, ${ }^{8}$ the venue (gym) is also used for social interaction and meeting potential partners. The incentive to perform intensive anaerobic training (IAT) is therefore strong, and some MSM spend long hours in gyms shaping their bodies, while some also adopt strict dietary regimens or are tempted to use anabolic steroids. ${ }^{9} 10$

Adults are recommended to perform $>150$ min of moderate-intensity or $>75 \mathrm{~min}$ of vigorous-intensity aerobic (endurance or cardio) activity a week. They are also recommended to perform muscle-strengthening (resistance or anaerobic) activity $>2$ days a week. ${ }^{11}$ In Israel, nearly $40 \%$ of all adult men aged 21-55 perform at least 20 min of physical activity $>3$ times a week, and gym activity is rated as the third most common method of exercise ( $21 \%$ of men). The reported main motivation to perform physical activity among Israeli men was health improvement, followed by recreational pleasure and body shaping (45\%, 35\% and $21 \%$, respectively). ${ }^{12}$

The incidence of HIV and sexually transmitted infections (STIs) in MSM is increasing in developed countries ${ }^{13}$ including Israel. ${ }^{14}$ Extensive research has been published on factors related to MSM sexual risk, aiming to understand their internal world and identify social constituents related to risk. ${ }^{13-15}$ One relatively less studied aspect is the role of physical activity in risk behaviour.

The present study aimed to associate physical activity and sexual behaviour among men in gyms in Tel Aviv by sexual orientation, and also to explore factors associating physical activity with psychological attributes and sexual-risk behaviour. We hypothesised that MSM would practise more IAT than heterosexual men, and that MSM who perform more IAT would be involved in highrisk behaviour, as their self-image is improved and they feel more confident in approaching potential sex partners.

\section{METHODS}

This cross-sectional study was performed in five gyms in central Tel Aviv between September and December 2012. Tel Aviv, like other metropolitan cities in developed countries, is characterised by a relatively open and liberal attitude towards MSM, thus it attracts most of the MSM-related activities in the country, ${ }^{16}$ in bars, parties and other venues, such as gyms.

\section{Participants}

Men living in central Israel who had trained for more than a month in one of the selected gyms, who were older than 18 years, and who reported more than one act of sexual intercourse in the preceding 6 months were eligible for this convenience sampling study.

Participants were asked to complete details on their sexual activities in the preceding 6 months. They were categorised as MSM if they performed sex (oral/anal intercourse) with other men, and as heterosexual if they performed sex (oral/vaginal/anal intercourse) exclusively with women. Those who reported sexual contact with both men and women were considered to be MSM in this study.

\section{Recruitment}

Gyms were visited using venue-based, time-space sampling methods, ${ }^{17}$ as the days and the times of visits were selected at random to include different days of the week and different hours of the day. A minimal sample size of 364 was required to allow a $5 \%$ difference in unprotected sex between MSM and heterosexual men in New York gyms, ${ }^{18}$ considering type 1 and 2 errors of $5 \%$ and $20 \%$, respectively. Male gym attendees were approached by one researcher (KP) and asked to complete the study questionnaire (see online supplementary appendix 1 ).

\section{Questionnaire}

After they had provided informed consent, participants individually gave their demographic characteristics and responded anonymously to 82 questions about their health and sexual behaviour, body image attributes, gym exercise pattern, reason for training, knowledge about HIV transmission, and other attitudes and beliefs about sexual-risk behaviour.

\section{Variables}

The first outcome variable was high-risk sexual behaviour, a self-report of at least one episode of unprotected anal or vaginal intercourse in the preceding 6 months with a partner whose HIV status was unknown or discordant. ${ }^{19}$ The second outcome variable was the intensity of IAT, defined as more than the median number of anaerobic training hours a week practised by all the study participants.

Body mass index (BMI) was calculated from selfreported height and weight, which could be confirmed using the gym's scales and measures during completion of the questionnaires. To evaluate indirectly the strength of motivation to achieve an attractive masculine body physique, participants were asked to imagine whether they would prefer to be rich or muscular, and similarly to decide between being rich and having a smooth body (Cronbach's $\alpha=0.87$ and 0.76 , respectively). Knowledge on HIV transmission was measured by grading responses (1=correct; 2=incorrect) to the following four statements: ${ }^{16} 20$ anal/vaginal sex without a condom is more dangerous than oral sex'; 'insertive oral sex is a safe 
practice with regard to HIV infection'; 'fingering a partner is a safe practice with regard to HIV transmission'; and 'body massage is a safe practice with regard to HIV/STI' (Cronbach's $\alpha=0.74$ ). The grades were totalled to create a composite score: the lower the score, the better the knowledge. The scores were dichotomised by the median score to those who demonstrated reasonable knowledge and those whose knowledge was insufficient. In order to measure negative affective status, the ULCA Loneliness Scale ${ }^{21}$ and the Sexual Sensation Seeking Scale $^{22}$ were used.

\section{Statistical methods}

Analyses were performed using $\chi^{2}$ or Fisher's exact tests for associating the categorical variables. Continuous variables were analysed by Student's t test or by the MannWhitney non-parametric test for variables distributed abnormally. Logistic analysis identifying variables predicting high-risk sexual behaviour or excessive anaerobic training included variables with $\mathrm{p}<0.05$ after assessment for collinearity and normal distribution in backwards fashion. The model generated ORs and 95\% CIs. Confounding between IAT, sexual risk and sexual orientation, as well as interaction between sexual orientation and IAT, among high-risk participants were assessed using 2-by-2 tables. Analysis was conducted using the SPSS V.17.0 package for Windows software. The study was approved by the $\mathrm{E}$ Wolfson Medical Centre Institutional Review Board (WOMC-0058-09).

\section{RESULTS}

Of approximately 600 men who were approached in five gyms in central Tel Aviv, 379 who were older than 18 years of age and reported more than one act of sexual intercourse in the preceding 6 months completed the questionnaire. Of these 379 men, $182(48 \%)$ were MSM (154 reported sex exclusively with men and 28 engaged in sex with both men and women), while 197 $(52 \%)$ were heterosexual. The mean $\pm \mathrm{SD}$ age of all the participants was $31.9 \pm 6$ (range 18-60) years.

\section{MSIM versus heterosexual men}

In comparison with heterosexual men, MSM were more likely to be Israeli-born, have lower BMI, have followed a dietary regimen, and used protein supplement powders or anabolic steroids (table 1). They also reported a greater number of casual sex partners and more commonly used drugs before or during sex. MSM demonstrated a stronger desire to become muscular (OR for preferring to be muscular than rich $3.0,95 \%$ CI 1.9 to $4.9, \mathrm{p}=0.01$ ), and a greater percentage reported performing IAT than heterosexual men. Body shaping and improving self-confidence were the main reasons of MSM for training, while losing weight and improving health were more predominant reasons among heterosexual men. The threat of HIV perceived by MSM was lower than that perceived by heterosexual men, yet
MSM considered themselves to be at higher risk of acquiring HIV/STI and had higher sexual desire scores than heterosexual men.

\section{High-risk versus non-high-risk participants}

High-risk participants were younger than those not at high risk, were more likely to smoke, and more commonly used protein supplement powders and anabolic steroids (table 2). A greater percentage of high-risk participants were MSM, had more sex partners, used drugs and were previously diagnosed with HIV/STI. They indicated a stronger desire to become muscular (OR for preferring to be muscular than rich $2.8,95 \%$ CI 1.7 to 4.6 ). Shaping their body and improving their self-confidence were their main reasons for training, and they also reported longer hours of anaerobic training. In addition, their knowledge on HIV transmission was inferior to that of non-high-risk participants, they demonstrated a more tolerant attitude towards HIV, and had higher sex desire and loneliness scores. In multivariate analysis, being an MSM, use of drugs and protein supplement powder, strong desire to become muscular, motivation to create a muscular and attractive body, and higher sexual desire score were predictive of high-risk sexual behaviour.

\section{Intensive versus non-intensive anaerobic training}

Participants who performed IAT were younger, had lower BMI, followed a dietary regimen, and more commonly used protein supplement powders than those who performed moderate anaerobic training (table 3). They were also more likely to be MSM and generally more involved in high-risk sexual behaviour. They were less satisfied with their body shape and demonstrated a stronger desire to have a muscular body. They indicated that their motivation to exercise was to improve their self-confidence and become more physically attractive than those who performed moderate anaerobic training, whose main motivations for training were improving their health and losing weight. Finally, those who performed IAT had a better knowledge of HIV transmission, reported that they were at higher risk of becoming infected with HIV, and had higher sexual desire scores. In multivariate analysis, being an MSM, young and dissatisfied with body shape, having a strong desire to be more attractive, having a high sexual desire score, and using protein supplement powders predicted IAT.

Of all 113 men who were defined as high risk, $61.9 \%$ $(\mathrm{N}=70)$ performed IAT, while $38.1 \%(\mathrm{~N}=43)$ performed moderate anaerobic physical activity $(\mathrm{p}<0.01)$. This association was stronger in MSM than heterosexual men ( $\mathrm{p}<0.01$ vs $\mathrm{p}=0.05$, respectively). The interaction between MSM and IAT among high-risk participants was multiplicative (see online supplementary appendix 2)that is, the effect of both being MSM and performing IAT on sexual risk is greater than the individual influence of each independent risk factor. 
Table 1 Characteristics of men who have sex with men and heterosexual men who train in Tel Aviv gyms

\begin{tabular}{|c|c|c|c|}
\hline Characteristic & $\begin{array}{l}\text { MSM } \\
(\mathrm{N}=182)\end{array}$ & $\begin{array}{l}\text { Heterosexual } \\
(\mathrm{N}=197)\end{array}$ & p Value \\
\hline \multicolumn{4}{|l|}{ Demography } \\
\hline Age & $31.5 \pm 5$ & $32.6 \pm 7$ & 0.05 \\
\hline Israeli born & $164(90.1)$ & $159(80.7)$ & 0.01 \\
\hline Academic education & $143(78.6)$ & $154(78.2)$ & 0.5 \\
\hline Income >US\$3000 per month & $85(47.7)$ & $96(48.7)$ & 1 \\
\hline \multicolumn{4}{|l|}{ Heath behaviour } \\
\hline Smoker & 89 (48.9) & $107(54.1)$ & 0.3 \\
\hline Pack years* & $5.6 \pm 7$ & $6.4 \pm 6$ & 0.5 \\
\hline $\mathrm{BMI}$ & $22.9 \pm 2$ & $23.9 \pm 3$ & $<0.001$ \\
\hline Special diet† & $98(54.1)$ & $97(49.2)$ & 0.03 \\
\hline Use protein supplement powders & $98(54.1)$ & $64(32.5)$ & $<0.001$ \\
\hline Shave body hair & $79(43.4)$ & $41(20.8)$ & $<0.001$ \\
\hline Use anabolic steroids & $10(5.5)$ & $0(0)$ & $<0.001$ \\
\hline \multicolumn{4}{|l|}{ Sexual behaviour in the last 6 months } \\
\hline Steady partner & $70(38.5)$ & $111(56.3)$ & 0.001 \\
\hline$>6$ sexual partners & $86(47.3)$ & $33(16.7)$ & $<0.001$ \\
\hline Paid for sex & $30(16.5)$ & $56(28.4)$ & 0.007 \\
\hline Performed sex in gym & $22(12.1)$ & $2(1.0)$ & $<0.001$ \\
\hline Drug use during sex & $123(67.6)$ & $88(44.7)$ & $<0.001$ \\
\hline HIV-infected & $3(1.8)$ & $2(1.6)$ & 1 \\
\hline STI in the past & $19(9.9)$ & $4(2.0)$ & $<0.001$ \\
\hline \multicolumn{4}{|l|}{ Body image } \\
\hline Satisfied & $32(17.6)$ & $34(17.3)$ & 1 \\
\hline Prefer to be smooth than rich & $42(23.5)$ & $12(6.2)$ & $<0.001$ \\
\hline Prefer to be muscular than rich & $81(45.3)$ & $41(21.4)$ & $<0.001$ \\
\hline \multicolumn{4}{|l|}{ Training } \\
\hline Number of weekly aerobic training hours & $3.1 \pm 2$ & $3.2 \pm 2$ & 0.4 \\
\hline Number of weekly anaerobic training hours & $5.0 \pm 3$ & $3.9 \pm 2$ & $<0.001$ \\
\hline \multicolumn{4}{|l|}{ Reason for training } \\
\hline Lose weight & $48(26.4)$ & $69(35.0)$ & 0.007 \\
\hline Shape body & $169(92.9)$ & $140(71.1)$ & $<0.001$ \\
\hline Improve self-confidence & $125(68.7)$ & $87(44.2)$ & $<0.001$ \\
\hline Improve health & $114(62.0)$ & $140(71.1)$ & 0.006 \\
\hline \multicolumn{4}{|l|}{ HIV knowledge, risk perception and loneliness } \\
\hline Sufficient knowledge about HIV transmission & $144(79.1)$ & $143(72.6)$ & 0.1 \\
\hline AIDS treatment optimism & $9(8.0)$ & $26(9.6)$ & 0.8 \\
\hline Commit suicide if diagnosed with HIV & $65(57.2)$ & $207(78.8)$ & 0.001 \\
\hline Can have HIV-infected partner & $95(84.1)$ & $169(64.2)$ & 0.001 \\
\hline Am at risk of having HIV & $29(25.7)$ & $10(3.7)$ & $<0.001$ \\
\hline Sexual Sensation Seeking Scale score & $15.6 \pm 6$ & $12.5 \pm 5$ & $<0.001$ \\
\hline UCLA Loneliness Scale score & $6.3 \pm 3$ & $6.1 \pm 2$ & 0.9 \\
\hline
\end{tabular}

Values are mean \pm SD or number (\%).

*Smokers only.

†Low-calorie diet, low-salt diet, low-protein diet.

BMI, body mass index; MSM, men who have sex with men; STI, sexually transmitted infection.

\section{DISCUSSION}

MSM who exercised in Tel Aviv gyms showed riskier sexual behaviour than heterosexual men and also demonstrated a stronger desire to develop a muscular body. To achieve this goal, their training programme included IAT, which showed multiplicative interaction with sexual risk.

\section{MSM and physical activity}

Most MSM in our study indicated that gym training was important in building their self-confidence and reported that their main reason for performing IAT was to increase their muscle mass thereby making them feel more desirable. In contrast, heterosexual men rated improvements in health and fitness as the most important reasons for training in the gym, in agreement with other publications. ${ }^{8} 23$

In our study, MSM who train in gyms expressed a high level of concern over their body image and believed that the results of their training enhanced their physical and sexual prowess. ${ }^{9}$ Pornography, which is more commonly used by MSM than heterosexual men, is full of 
Table 2 Comparison between high-risk and non-high-risk participants who train in Tel Aviv gyms

\begin{tabular}{|c|c|c|c|c|}
\hline \multirow[b]{2}{*}{ Characteristic } & \multicolumn{3}{|l|}{ Univariate } & \multirow[b]{2}{*}{$\begin{array}{l}\text { Multivariate } \\
\text { OR }(95 \% \mathrm{Cl})\end{array}$} \\
\hline & $\begin{array}{l}\text { High-risk } \\
(\mathrm{N}=113)\end{array}$ & $\begin{array}{l}\text { Non-high-risk } \\
(\mathrm{N}=266)\end{array}$ & p Value & \\
\hline \multicolumn{5}{|l|}{ Demography } \\
\hline Age & $30.6 \pm 5$ & $32.4 \pm 6$ & 0.01 & \\
\hline Israeli born & $96(85.0)$ & $227(85.3)$ & 0.9 & \\
\hline Academic education & $84(74.3)$ & $230(80.1)$ & 0.2 & \\
\hline Income >US $\$ 3000$ per month & $36(32.4)$ & $102(38.6)$ & 0.2 & \\
\hline \multicolumn{5}{|l|}{ Heath behaviour } \\
\hline Smoker & $49(43.4)$ & $74(27.8)$ & 0.002 & \\
\hline Pack years* & $4.3 \pm 4$ & $7.0 \pm 7$ & 0.001 & \\
\hline $\mathrm{BMI}$ & $23.4 \pm 2$ & $23.5 \pm 2$ & 0.8 & \\
\hline Special diet† & $56(52.8)$ & $129(51.2)$ & 0.8 & \\
\hline Use of protein supplement powders & $57(50.9)$ & $105(39.5)$ & 0.03 & 2.5 (1.7 to 4.5$)$ \\
\hline Use of anabolic steroids & $6(5.2)$ & $4(1.5)$ & 0.05 & \\
\hline \multicolumn{5}{|l|}{ Sexual behaviour in the last 6 months } \\
\hline MSM & $88(77.8)$ & $108(48.0)$ & $<0.001$ & 1.7 (1.1 to 2.9$)$ \\
\hline Steady partner & $25(22.1)$ & $156(58.6)$ & $<0.001$ & \\
\hline$>6$ sexual partners & $62(54.9)$ & $21(7.9)$ & $<0.001$ & \\
\hline Paid for sex & $26(23.0)$ & $60(22.6)$ & 1.0 & \\
\hline Perform sex in gym & $15(13.2)$ & $9(3.3)$ & $<0.001$ & \\
\hline Drug use during sex & 87 (77.0) & $124(46.6)$ & $<0.001$ & $1.3(1.2$ to 1.7$)$ \\
\hline HIV-infected & $4(4.2)$ & $1(0.5)$ & $<0.001$ & \\
\hline \multicolumn{5}{|l|}{ Body image } \\
\hline STI in the past & $13(11.5)$ & $10(3.6)$ & $<0.001$ & \\
\hline Satisfied & 94 (83.2) & $234(88.0)$ & 0.2 & \\
\hline Prefer to be smooth than rich & $24(21.2)$ & $30(11.5)$ & 0.02 & \\
\hline Prefer to be muscular than rich & $55(49.1)$ & 67 (25.9) & $<0.001$ & 1.7 (1.1 to 3.0$)$ \\
\hline \multicolumn{5}{|l|}{ Reason for training } \\
\hline Lose weight & $34(30.1)$ & $83(31.2)$ & 0.9 & \\
\hline Shape body & $107(94.7)$ & $202(75.9)$ & $<0.001$ & $2.3(1.2$ to 4.5$)$ \\
\hline Improve self-confidence & $78(69.0)$ & $134(50.4)$ & 0.01 & \\
\hline Improve health & $75(66.4)$ & $187(70.3)$ & 0.5 & \\
\hline \multicolumn{5}{|l|}{ Training } \\
\hline Number of weekly aerobic training hours & $3.3 \pm 1.9$ & $3.1 \pm 1.7$ & 0.4 & \\
\hline Number of weekly anaerobic training hours & $4.8 \pm 2.7$ & $4.2 \pm 2.2$ & 0.03 & \\
\hline \multicolumn{5}{|l|}{ HIV knowledge, risk perception and loneliness } \\
\hline Sufficient knowledge about HIV transmission & $74(65.5)$ & $213(80.1)$ & $<0.001$ & \\
\hline AIDS treatment optimism & $46(40.7)$ & $74(27.8)$ & 0.02 & \\
\hline Commit suicide if diagnosed with HIV & $75(68.2)$ & $197(74.9)$ & 0.2 & \\
\hline Can have HIV-infected partner & $61(33.7)$ & $21(10.8)$ & $<0.001$ & \\
\hline Am at risk of having HIV & $36(19.8)$ & $3(1.5)$ & $<0.001$ & \\
\hline Sexual Sensation Seeking Scale score & $16.6 \pm 6$ & $12.8 \pm 5$ & $<0.001$ & 2.8 (1.5 to 5.2$)$ \\
\hline UCLA Loneliness Scale score & $6.6 \pm 2$ & $6.1 \pm 3$ & 0.04 & \\
\hline $\begin{array}{l}\text { Values are mean } \pm \text { SD or number }(\%) \text {. } \\
\text { *Smokers only. } \\
\text { †Low-calorie diet, low-salt diet, low-protein diet. } \\
\text { BMI, body mass index; MSM, men who have sex with }\end{array}$ & - & ed infection. & & \\
\hline
\end{tabular}

mesomorphic, muscular, and highly athletic 'porn stars' with smooth bodies. ${ }^{1}$ Viewers may internalise the messages and embrace the belief that they need to possess a similar physique in order to obtain sexual gratification. In addition, MSM-oriented internet sites, which are used as the major platform for searching out other MSM, encourage web participants to upload their own body images. This is an additional external motivation to attain 'ideal' muscular aesthetics, while enhancing their attractiveness and securing their MSM identity. It has previously been suggested that MSM who are satisfied with their body express higher well-being scores and selfesteem, while those who fail to achieve this physical model may be more depressed and isolated. ${ }^{24}$

It has been well documented that physical activity reduces morbidity and preserves health. ${ }^{11}$ Although both aerobic and anaerobic training are important components of achieving physical fitness, some men in our study performed IAT disproportionally. Gym coaches can be trained to identify men who perform 
Table 3 Comparison between participants who perform intensive and non-intensive anaerobic training in Tel Aviv gyms

\begin{tabular}{|c|c|c|c|c|}
\hline \multirow[b]{2}{*}{ Characteristic } & \multicolumn{3}{|l|}{ Univariate } & \multirow[b]{2}{*}{$\begin{array}{l}\text { Multivariate } \\
\text { OR }(95 \% \mathrm{Cl})\end{array}$} \\
\hline & $\begin{array}{l}\text { More than the } \\
\text { median (>4 } \mathrm{h} \text { a week) } \\
(\mathrm{N}=214)\end{array}$ & $\begin{array}{l}\text { Less than the } \\
\text { median ( } \leq 4 \mathrm{~h} \text { a week) } \\
(\mathrm{N}=165)\end{array}$ & p Value & \\
\hline \multicolumn{5}{|l|}{ Demography } \\
\hline Age & $30.2 \pm 5$ & $33.2 \pm 7$ & $<0.001$ & 0.7 (0.6 to 0.9$)$ \\
\hline Israeli born & $144(87.3)$ & 179 (83.6) & 0.7 & \\
\hline Academic education & $133(80.6)$ & $164(76.6)$ & 0.4 & \\
\hline Income >US\$3000 (month) & $54(33.5)$ & $84(39.3)$ & 0.1 & \\
\hline \multicolumn{5}{|l|}{ Heath behaviour } \\
\hline Smoker & $59(35.8)$ & $64(29.9)$ & 0.2 & \\
\hline Pack years* & $6.3 \pm 8$ & $5.8 \pm 5$ & 0.7 & \\
\hline $\mathrm{BMI}$ & $23.0 \pm 2$ & $23.7 \pm 2$ & 0.04 & \\
\hline Special diet† & $106(67.9)$ & $79(39.1)$ & 0.001 & \\
\hline Use of protein powders & $100(61.0)$ & $62(29.0)$ & 0.001 & $2.5(1.7$ to 3.8$)$ \\
\hline Use of anabolic steroids & $6(3.6)$ & $4(1.9)$ & 0.3 & \\
\hline \multicolumn{5}{|l|}{ Sexual behaviour in the last 6 months } \\
\hline MSM & $97(58.8)$ & $85(39.7)$ & $<0.001$ & $1.8(1.1$ to 2.8$)$ \\
\hline Steady partner & $72(43.6)$ & $134(76.6)$ & $<0.001$ & \\
\hline$>6$ sexual partners & $75(45.5)$ & $27(12.6)$ & 0.01 & \\
\hline Paid for sex & $39(23.6)$ & $47(22.0)$ & 0.7 & \\
\hline Perform sex in gym & $14(8.5)$ & $10(4.7)$ & 0.1 & \\
\hline Drug use during sex & $106(64.2)$ & $105(49.1)$ & 0.04 & \\
\hline HIV-infected & $1(0.7)$ & $4(2.6)$ & 0.05 & \\
\hline STI in the past & $13(7.9)$ & $9(4.2)$ & 0.1 & \\
\hline \multicolumn{5}{|l|}{ Body image } \\
\hline Satisfied & $132(80.0)$ & $196(91.6)$ & 0.001 & 2.3 (1.1 to 4.6$)$ \\
\hline Prefer to be smooth than rich & $31(19.3)$ & $23(10.8)$ & 0.02 & \\
\hline Prefer to be muscular than rich & 75 (46.3) & $47(22.5)$ & $<0.001$ & 1.9 (1.3 to 3.3$)$ \\
\hline \multicolumn{5}{|l|}{ Reason for training } \\
\hline Lose weight & $28(17.0)$ & $89(41.6)$ & 0.01 & \\
\hline Shape body & $161(97.6)$ & $199(93.0)$ & 0.04 & \\
\hline Improve self-confidence & $105(63.6)$ & $107(50.0)$ & 0.002 & 2.8 (1.8 to 4.5$)$ \\
\hline Improve health & 101 (61.2) & $162(75.2)$ & 0.003 & \\
\hline \multicolumn{5}{|l|}{ HIV knowledge, risk perception and loneliness } \\
\hline Sufficient knowledge about HIV transmission & $173(80.8)$ & $114(69.1)$ & 0.02 & \\
\hline AIDS optimism & 117 (70.9) & $142(66.4)$ & 0.06 & \\
\hline Commit suicide if diagnosed with HIV & $116(71.6)$ & $156(73.9)$ & 0.6 & \\
\hline Can have HIV-infected partner & $43(26.2)$ & $39(18.4)$ & 0.07 & \\
\hline Am at risk of having HIV & $23(13.9)$ & $16(7.5)$ & 0.04 & \\
\hline Sexual Sensation Seeking Scale score & $15 \pm 6$ & $13 \pm 5$ & $<0.001$ & $1.2(1.1$ to 1.4$)$ \\
\hline UCLA Loneliness Scale score & $6.4 \pm 3$ & $6.1 \pm 2$ & 0.3 & \\
\hline
\end{tabular}

excessive anaerobic exercise, and can then recommend that such men balance their different sporting activities to achieve better health results or emphasise a more self-directed approach of accepting their bodies. Gym premises can also be used to deliver safe-sex messages targeting MSM.

\section{Risk taking and physical activity}

The association found in our study between high-risk sexual behaviour and IAT is in agreement with other publications. ${ }^{25} 26$ This effect was multiplicative among MSM.
MSM who are more muscular, as a result of IAT or the use of anabolic steroids, are considered more attractive and may be more self-confident. ${ }^{27}$ They are therefore able to increase their repertoire of partners and their involvement in sexual adventurism, thereby increasing their risk of acquiring HIV/STI (figure 1). Health promotion professionals and homosexual community leaders should consider initiating debate regarding the preoccupation of MSM with their body image and related sexual adventurism, which places them at increased sexual risk and at the same time exposes them to possible sport injuries. 


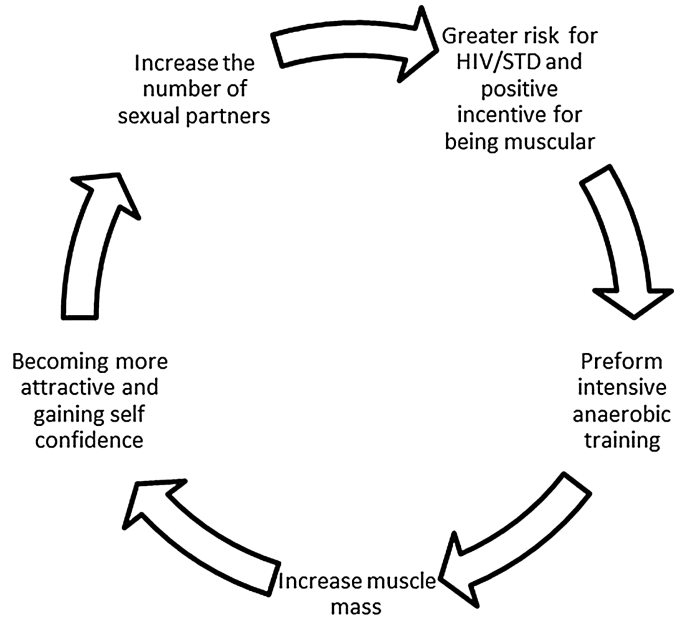

Figure 1 Model suggesting association between sexual risk, anaerobic physical activity and muscle mass among men who have sex with men.

\section{Heterosexual and physical activity}

Unlike other publications, ${ }^{8}{ }^{18}$ no differences were found in our study in the reported level of body satisfaction between MSM and heterosexual men. However, those who indicated that they are dissatisfied with their body image in our study did perform IAT.

Unlike MSM, heterosexual men thought that wealth was a more important factor for attracting and keeping sexual partners than body physique. The results of this study open a window to the contemporary heterosexual man's perception of his own body image. Unlike MSM and women, heterosexual men are not used to viewing their bodies in objective and sexual terms. ${ }^{8}$ However, along with the greater societal acceptance of MSM in the hetero-normative community, heterosexual men are constantly exposed to the MSM 'ideal' body image. Heterosexual men have become more conscious of their appearance and make similar efforts to MSM to achieve the muscular body 'ideal', which has been termed 'metrosexuality'. As found in our study, and similarly to MSM, they buy clothes and cosmetics in designated male shops, and are relatively more aware of their body shape and body hair. It may be possible that the preoccupation of heterosexual men with their body shape may lead some to experience similar dynamics to MSM, exposing them to risk of HIV/STI.

This study has certain limitations. First, it was based on non-probability sampling, which may limit its generalisability. However, other publications have found similar behaviours among MSM in studies from gym sampling and from homosexual social venues or treatment facilities. ${ }^{7}$ In order to reduce selection bias, the various gyms and the times visited were selected randomly to increase the number of clientele available for this study. Second, men who performed IAT possibly frequented gyms more often than those who did not. In order to reduce possible selection bias, independent variables were analysed for possible covariates. Third, this study focuses only on MSM who train in gyms. However, it provided a valid comparison between MSM and heterosexual men regarding gym practices. Fourth, our data are selfreported and subject to reporting and recall bias. To reduce this bias, most items on the questionnaire were relevant for the preceding 6 months. Fifth, participants who performed unprotected sex with HIV-infected partners were considered 'at risk' even if the partner had received antiretroviral therapy. However, owing to the relatively low HIV rate in Israel, we believe that this differential misclassification of information bias, if it occurs, is minimal. Sixth, the limited number of men who reported sex with both men and women did not allow a separate statistical analysis to be conducted to indicate their risk. Despite these limitations, this is the first study performed in Israeli gyms on non-MSMoriented premises. As MSM in developed countries share similar cultural norms and behaviours, the results of this study and the multiplicative interaction between IAT (reflected by body image) with sexual risk may be used by other health professionals who wish to perform risk-reduction interventions among MSM.

In summary, this study demonstrates that some MSM attending gyms practise IAT and also that the interaction between IAT and sexual risk behaviour among MSM is multiplicative. MSM who are muscular and more attractive improve their self-esteem and are able to meet more sexual partners, thereby increasing their risk of HIV/STI. The gym culture in the homosexual community is an example of how internal dynamics and social norms are possible factors driving MSM to higher risk of HIV/STI. The homosexual community would benefit from a more holistic approach to sexual health by addressing body image and physical training and possible health outcomes. In addition, gym premises could be used to distribute safe-sex messages, in order to improve knowledge about HIV transmission, as gyms are often frequented by MSM involved in risky sexual behaviour. Future research could compare risk behaviours between MSM who exercise regularly in gyms and those who do not, or with other MSM who engage in sport activities other than gyms, to determine whether similar conclusions can be drawn from different recreation activities.

Contributors ZM: initiated the study, performed data analysis, and wrote the first draft. KP: performed a literature review and collected and analysed the data. ND: supervised analysis and participated in writing. IG: revised the paper and approved the final version. YL: analysed the data.

Funding This research received no specific grant from any funding agency in the public, commercial or not-for-profit sectors.

Competing interests None.

Patient consent Obtained.

Ethics approval Wolfson Hospital IRB.

Provenance and peer review Not commissioned; externally peer reviewed.

Data sharing statement All data collected from study questionnaires are available by contacting the corresponding author: zohar.mor@rml.health.gov.il. 
Open Access This is an Open Access article distributed in accordance with the Creative Commons Attribution Non Commercial (CC BY-NC 4.0) license, which permits others to distribute, remix, adapt, build upon this work noncommercially, and license their derivative works on different terms, provided the original work is properly cited and the use is non-commercial. See: http:// creativecommons.org/licenses/by-nc/4.0/

\section{REFERENCES}

1. Lanzieri N, Hildebrandt T. Using hegemonic masculinity to explain gay male attraction to muscular and athlete men. $J$ Homosexuality 2011;58:275-93.

2. Badinter E. XY: on masculinity identity. (L. Davis, Trans) New York, NY: Columbia University Press, 1995.

3. Sharon G. Body image, well-being and sexual satisfaction: a comparison between heterosexual and gay men. Sex Relationship Ther 2007;22:238-44.

4. Green Al. Health and sexual status in an urban gay enclave: an application of the stress process model. J Health Soc Behav 2008;49:436-51.

5. Halikits PN. Masculinity in the age of AIDS seropositive gay men and the "buff agenda". In: Nardi P, ed. Coming on strong: gay masculinities. Newbury Park, CA: Sage, 1999:130-51.

6. Rubinstein G. Macho man: narcissism, homophobia, agency, communition, and authoritarianism-a comparative study among Israeli bodybuilders and a control group. Psychol Men Masculinity 2007:4:100-10.

7. Halkitis PN. Masculinity, body image, and sexual behavior in HIV-seropositive gay men: a two-phase formative behavioral investigation using the internet. Int J Mens Health 2004;3:27-42.

8. Brown J, Graham D. Body satisfaction in gym-active males: an exploration of sexuality, gender and narcissism. Sex Roles 2008;59:94-106.

9. Bolding G, Sherr L, Elford J. Use of anabolic steroids and associated health risks among gay men attending London gyms. Addiction 2001;97:195-203.

10. Yang F, Gray P, Pope HG Jr. Male body image in Taiwan versus the west: Yanggang Zhiqi meet Adonis complex. Am J Psychiatry 2005;162:263-9.

11. U.S. Department of Health and Human Services. Physical Activity Guidelines for Americans. http://www.health.gov/paguidelines/ factsheetprof.aspx (accessed 19 May 2013).

12. Israeli Centres for Disease Control and Prevention. Health Status in Israel. Tel Hashomer, Israel: Ministry of Health, Publication \#333, 2011.
13. Fenton KA, Imrie J. Increasing rates of sexually transmitted diseases in homosexual men in Western Europe and United States: why? Infect Dis Clin North Am 2005;19:311-31.

14. Mor Z, Weinstein R, Grotto I, et al. Thirty years of HIV in Israelcurrent epidemiology and future challenges. BMJ Open 2013;3. e003078.

15. Elford J, Bolding G, Sherr L. High- risk sexual behavior increase among London gay men between 1998 and 2001: what is the role of HIV optimism? AIDS 2000;16:1537-44.

16. Mor Z, Davidovich U, Bessudu-Manor N, et al. High risk behavior in steady and in casual relationships among men who have sex with men in Israel. Sexually Transm Infect 2011;87:532-7.

17. MacKellar DA, Gallasgher K Finlayson T, et al. Surveillance of HIV risk and prevention behaviors of men who have sex with men-a national application of venue-based, time-space sampling. Public Health Rep 2007;122:39-47.

18. Halkitis PN, Moeller RW, Siconolfi DE, et al. Sexual practices of gay, bisexual, and other non-identified MSM attending New York City gyms: patterns of serosorting, strategic positioning, and context selection. J Sex Res 2000;45:253-61.

19. Mor Z, Dan M. Knowledge, attitudes, sexual practices and STI/HIV prevalence in male sex workers and other men who have sex in Tel-Aviv, Israel: a cross sectional study. Sex Transm Infect 2012;88:574-80.

20. Mor Z, Davidovich U, McFarlane M, et al. Gay men who engage in substance use and sexual risk behavior: a dual risk-group with unique characteristics. Int J STD AIDS 2008;19:698-703.

21. Russell DW. ULCA Loneliness Scale (version 3): reliability, validity, and factor structure. J Pers Assess 1996;66:20-40.

22. Kalichman SC, Johnson JR, Adair V, et al. Sexual sensation seeking: scale development and predicting AIDS-risk behavior among homosexually active men. J Pers Assess 1994;62: 385-97.

23. Duggan SJ, McCreary DR. Body image, eating disorders, and the drive for muscularity in gay and heterosexual men: The influence of media images. J Homosexuality 2004;47:45-58.

24. Duncan D. Out of the closet and into the gym: gay men and body image in Melbourne, Australia. J Mens Stud 2008;15:331-46.

25. Kraft C, Robinson BB, Nordstrom DL, et al. Obesity, body image and unsafe sex in men who have sex with men. Arch Sex Behav 2006;35:587-95.

26. Allensworth-Davies D, Welles SL, Hellerstedt WL, et al. Body image, body satisfaction, and unsafe anal intercourse among men who have sex with men. J Sex Res 2008;45:49-56.

27. Shilo G, Mor Z. The impact of minority stressors on the mental and physical health of LGB youth and young adults. Health Soc Work 2014;39:161-71. 